\title{
Fintech, Digital Payments, and the Risks of Outsourcing Payroll Accounting: The Case of MyPayRollHR
}

\author{
Uma V. Sridharan \\ Columbus State University
}

Payroll accounting requires specialized knowledge and expertise that many small businesses lack. Employee recruitment, retention and satisfaction are highly dependent on the employer's ability to efficiently process payroll in a timely and dependable fashion. Firms outsource payroll to devote more time and resources on their primary business and strategic goals which may have a bigger impact than processing payroll does, on the firm's triple bottom line-people, profit, and the planet. While the decision to outsource payroll can help ensure employees are paid and taxes are withheld in a timely fashion, there are inherent risks in handing off this important function to a third-party processor. The ultimate responsibility for accurate and timely processing of payroll remains with the employer. So, firms seeking to outsource payroll need to perform adequate due diligence to ensure there are proper financial controls at third party payroll processors to prevent fraud and misappropriation. This paper presents a recent real life case study that explains the potential pitfalls of outsourcing the payroll function especially when digital payments are used.

Keywords: payroll accounting, digital payments, outsourcing payroll, Fintech, ACH

\section{INTRODUCTION}

Payroll processing is an important function in any organization as it is directly tied to employee satisfaction. To retain employees and have their loyalty and commitment, firms need to make sure they pay their employees their due wages on time. However, payroll accounting and processing involves many repetitive tasks that require much knowledge of the law and accounting. Payroll accounting also requires expertise in dealing with financial institutions involved in processing the payments to employees. To process payroll correctly, a firm has to have an updated list of all its employees, information on the contracted wages for each employee, overtime pay, bonus and commissions (as applicable) and information on employee benefits (such as insurance and retirement benefits). The payroll processor must correctly deduct taxes due to federal and state governments and remit the same to governmental authorities. Above all, firms must ensure employees are paid their due in a timely fashion. Many small and medium sized enterprises (SMEs) do not have the time and the expertise to perform all the tasks of managing and processing payroll for their employees, nor is it cost effective for them to hire HR and accounting staff to perform these tasks for them in-house. Therefore, this task is often outsourced to third parties with specialized skill and expertise in the field. However, if this job is not outsourced to a responsible third party, in the absence of adequate checks and controls, there is opportunity for fraud leading to great employee dissatisfaction. This paper presents a case study of payroll processing fraud. It is useful reading for students 
of HR as well as SME managers contemplating the outsourcing of the payroll function. It will help the reader to understand this particular type of fraud and, the risks associated with outsourcing payroll, the risks of using digital payments (fintech) and the controls necessary to prevent this kind of fraud. Managers at many small and medium sized enterprises (SME) may not fully grasp the intricacy of the payroll process and the necessary internal controls for safe and effective payroll processing, and this paper maybe useful to them. This paper fills a gap in the literature that ties compensation and benefits payments to digital payments fraud. This paper has particular relevance in a business environment that has been rapidly and dramatically reshaped by Covid-19 as explained in the next paragraph.

Fintech refers to the use of technology to provide financial services. The Fintech space has been growing rapidly since 2008. Digital payments are an application of Fintech. Even before the Covid-19 pandemic there had been a steep rise in Fintech and the use of digital payments. Since the pandemic of 2020, people and companies have increasingly veered away from using paper checks and other paper documents and prefer contactless options. There is a growing preference to lessen physical encounters to lessen Covid-19 risk as well as to increase speed and efficiency in payments. In the absence of controls, this preference for Fintech, could contribute to an increase in payment fraud. The fraud in the My PayrollHR case was possible since the firm used Fintech or digital payments and internal controls were missing. While Fintech has many advantages such as minimizing float and reducing delays in making payments, there are serious fraud risks with Fintech payments as outlined in this paper. These fraud risks however can be mitigated with appropriate due diligence and controls.

\section{RESPONSIBILITIES OF PAYROLL PROCESSING}

To manage payroll properly in-house, the employer must keep track of all employees that have been newly hired as well as those that have been furloughed or dismissed. The employer must have a correct accounting of all the hours worked by each employee as well as the distinction between part time and fulltime employees as they may accrue differential benefits. The employer must keep track of changes in federal and state law and regulations as they impact employment and wages, including changes in withholding rates and government forms.

Another important responsibility associated with payroll is the safekeeping of employee data. Payroll data is highly sensitive and confidential. Unauthorized access to employee data opens the door to identity theft. Employers who manage their own payroll need to have clear separation of duties among employees who manage various payroll related functions including preparing of payroll data, approving payroll actions, reviewing periodic payroll expense reports and reconciliation of monthly financial records. Employees should not be able to oversee or approve actions that affect their own paychecks. Lack of separation of duties could lead to unauthorized or fraudulent payments, improper charges to accounts, inaccurate entries made to financial records and the resulting inability to make payroll payments when they are due. For these reasons, small firms with limited resources often make the choice to outsource payroll processing, as stated by Lubetkin, 2015.

"Many accountants are realizing the value of payroll services and increasingly using online payroll service providers to improve client service, increase loyalty and generate additional revenue year-round." (Lubetkin, 2015)

However, the decision to outsource payroll is not a simple one. According to Andrew Childs, VP of Marketing for Paychex, "When evaluating a potential payroll provider, it's important to consider what offerings are going to add the most value to the client." (Childs, et al., 2015)

\section{FINTECH AND DIGITAL PAYMENTS}

For about one hundred years, before the advent of digital payments, firms paid their employees by checks printed on paper. Employees would receive their checks in the mail or via the office mailbox and 
they had to take them to the bank to deposit the check. If the employee's bank was different from the employer's bank, there could be delays in the employee getting access to their money due to time necessary for check verification. Paper checks can be stolen or lost causing inconvenience to the employee and employer alike. If an employee lost a paper paycheck, they would have to go through the employer to get a replacement check and the process of getting a replacement check could take several days. The delay would be worse if someone else found the lost check and managed to cash it. Unfortunately, check fraud is a common form of payments fraud and checks are sometime successfully cashed by people without proper authorization. With a direct deposit of payroll, such inconveniences to employer and employee alike are avoided. However, for a direct deposit employees would have to provide the employer with their bank information to permit the employer to directly deposit their earned compensation to their bank accounts. Some employees may be reluctant to be required to share such personal information, but most are not. It is estimated roughly eighty two percent of employees in the USA receive their paycheck via direct deposit of payroll.

"In the 1960s, improvements in telecommunications and computers sparked the first age of electronic payments in the USA, leading to the development of the Automated Clearing House network" (Laverdure \& Mills, 2019.) In 1968, check clearing associations worked together to create an automated payment system on account of the very large number of payroll checks being processed. The first Automated Clearing House or ACH was formed in 1972 in California, and subsequently there were automated clearing houses formed in other states within the USA. The National Automated Clearing House Association (NACHA) was formed in 1974 to regulate the network of automated clearing houses. Since 1978, the ACH network provided a nationwide network for transferring money electronically. Bauer and Ferrier (1996) report while "cash comprises about $80 \%$ of the volume of transactions in the United States, it accounts for less than $1 \%$ of the value. Automated Clearing House (ACH) Transfers, checks and wire transfers combined account for $99 \%$ of the value transferred by the payment system. As computer and telecommunication technologies evolved and developed, increasingly firms switched over to electronic direct deposit of paychecks. According to Dun and Bradstreet there are about 5900 firms in the US payroll services industry and the annual revenue of these firms is about USD 30 billion. Five publicly traded firms in this industry include ADPTotalSource, Paychex, Insperity, Trinet, and Barret Business Services. A brief summary of the size of these firms is provided in Table 1 below.

TABLE 1

\section{SUMMARY OF PUBLIC FIRMS IN THE US PAYROLL SERVICES INDUSTRY}

(ALL FIGURES IN USD)

\begin{tabular}{|l|l|r|r|r|r|}
\hline \multicolumn{1}{|c|}{ FIRM } & \multicolumn{1}{|c|}{$\begin{array}{c}\text { MARKET } \\
\text { CAP }\end{array}$} & $\begin{array}{c}\text { P/E } \\
\text { RATIO }\end{array}$ & $\begin{array}{c}\text { W2 } \\
\text { WEEK } \\
\text { HIGH }\end{array}$ & $\begin{array}{c}\text { W2 } \\
\text { WEEK } \\
\text { LOW }\end{array}$ & CURRENT \\
\hline ADP TOTALSOURCE & $59.22 \mathrm{~B}^{*}$ & 36.97 & 153.51 & 107.61 & 135.13 \\
\hline PAYCHEX (PAYX) & $25.12 \mathrm{~B}^{*}$ & 26.12 & 76.02 & 59.36 & 69.95 \\
\hline INSPERITY (NSP) & $4.23 \mathrm{~B}$ & 48.69 & 121.15 & 55.4 & 101.21 \\
\hline TRINET GROUP (TNET) & $3.21 \mathrm{~B}$ & 18.28 & 60.15 & 38.26 & 45.59 \\
\hline $\begin{array}{l}\text { BARRETT BUSINESS } \\
\text { SERVICES (BBSI) }\end{array}$ & $0.43 \mathrm{~B}$ & 16.83 & 98.76 & 53.1 & 58.69 \\
\hline
\end{tabular}

Source: http://netprofitgrowth.com/publicly-traded-peo-comparison/

According to Dun and Bradstreet the 50 largest firms in the industry account for only about seventy percent of the industry revenue with thirty percent of industry revenue generated by smaller regional firms.

The mechanics of the direct deposit of payroll is as follows. The employer requires the employee to provide information such as the name of the receiving depository financial institution (RDFI), the type of account held by the employee, the RDFI's ABA or bank routing number and the employee's account number. The ABA is a nine-digit code that uniquely identifies the bank in the banking system. A bank's 
ABA number is typically printed on every check and is the nine-digit number located at the lower left hand corner of a personal check. To ensure accuracy most employers require employees participating in a direct deposit of payroll to provide a voided check.

In any $\mathrm{ACH}$ payment there are several players. The $\mathrm{ACH}$ payment is initiated by an originator, which is typically the payroll company acting on behalf of the employer, if the payroll function has been outsourced. The originator's depository financial institution (ODFI) then submits the ACH entry on behalf of the originator to the $\mathrm{ACH}$ operator. $\mathrm{ACH}$ entries are typically submitted in batches, and it is up to the $\mathrm{ACH}$ operator to sort them out. The $\mathrm{ACH}$ operator transmits the ACH entries to the RDFI. The RDFI typically checks to see if there are sufficient funds in the ODFI and pulls the funds from the ODFI. While federal consumer protection laws protect consumer accounts from errors in electronic transfers, business accounts are not similarly protected. Unlike wire transfers which happen immediately and are not reversible, $\mathrm{ACH}$ transfers can be reversed. NACHA allows the $\mathrm{ACH}$ transaction to be easily reversed if there was an error in the amount transferred, an error in the account number, or if a duplicate transaction was made in error. A previously authorized transaction can be revoked. According to NACHA, in 2016, eighty two percent of American workers were paid via ACH compared to seventy four percent in 2011.

\section{THE FRAUD AT MYPAYROLL HR}

About four thousand small and medium sized firms across the United States outsourced their payroll processing to MyPayRollHR, which was a limited liability firm incorporated in Massachusetts, USA. The firm was based in Clifton Park, NJ, and was the subsidiary of another firm by name ValueWise. My PayRollHR worked with Cachet Financial Services, a California based third party ACH Payroll processor, who would make payments to the employees of the clients of MyPayrollHR. MyPayrollHR did the payroll accounting for its clients who would periodically deposit wages due to their employees with MyPayrollHR. Every two weeks, on Wednesday, as payroll obligations would come due, MyPayrollHR would arrange for the funds deposited by MyPayrollHR clients to be transferred to a holding account that was owned by ACH Operator Cachet Financial Services. MyPayrollHR would send Cachet Financial Services a digital file showing all amounts deposited with it by clients and the amounts to be paid to each client employee. Per the instructions in this digital file, financial institutions for MyPayrollHR's clients (RDFI) would pull the funds from Cachet's holding account.

For over twelve years payroll disbursements were made as expected, but on Wednesday, September 4, 2019, MyPayrollHR instructed its bank that the funds in the account holding its client payments, be transferred to an account with Pioneer Savings Bank that was controlled by Michael Mann, CEO of MyPayrollHR. The payroll deposits made by the clients of MyPayrollHR were not transferred as usual to the Cachet holding account. On Sept 6, 2019, per the instructions in the digital file sent to Cachet by MyPayrollHR, receiving depository financial institutions (RDFIs) for MyPayrollHR's clients pulled \$26 million from Cachet's holding account. When Cachet discovered it had disbursed \$26 million that it had not received in the holding account for MyPayrollHR, it attempted to recover the \$26 million pulled from it by RDFIs. According to Cachet's legal counsel, the initial reversal request submitted by Cachet was not correctly formatted per the rules of the NACHA. So, Cachet submitted a second correctly coded request. However, many financial institutions ended up processing both reversal requests resulting in a month's worth of wages being withdrawn from MyPayrollHR clients' employee bank accounts instead of the employees receiving wages due to them. This caused severe distress and much loud protest from

MyPayrollHR client employees. In response to these protests, Cachet cancelled all the reversals and decided to seek redress via the courts for its \$26 million loss. Per NACHA's rules Cachet was not permitted to reverse the $\mathrm{ACH}$ payments due to a funding failure.

A summary of the timeline of events is presented below:

1. Sept 4, 2019: My PayrollHR instructed its financial institution to transfer client payroll funds to Michael Mann's account in Pioneer Savings bank instead of transferring funds to ACH operator Cachet Holding Services. 
2. Sept 4/5, 2019: My PayrollHR sent digital file to Cachet Holding Services instructing Cachet on how funds were to be disbursed to employees of its client firms.

3. Sept 6, 2019: Receiving Depository Financial Institutions (RDFI) pulled payroll funds to the tune of \$26 million from Cachet Holding Services to pay employees of clients of MyPayroll HR.

4. Sept 6, 2019: Cachet submitted first wrongly coded request to reverse unfunded payroll transfer and processed by some RDFI.

5. Sept 6, 2019: Cachet submitted second correctly coded request to reverse unfunded payroll transfer- processed by some RDFI.

6. Sept 6, 2019: Some employees of MyPayrollHR clients discover that not only did they not get paid on September 6, but funds equivalent to one paycheck were withdrawn from their bank accounts on the day they were to receive a paycheck.

7. Cachet cancels all reversals and seeks redress from courts for the lost \$26 million.

Later, in September 2019, MyPayrollHR shuttered its offices and posted the following on its website:

"Dear Client: due to unforeseen circumstances we are no longer able to process any further payroll transactions. Please find alternative methods to process your payrolls. For any payroll batches submitted during the week, including any payroll reversals from last week, please be prepared to find an alternative method to pay employees. We are working to release any funds that are in transit as a result of this matter. We will provide you with updates via this medium as we receive them."

National Payment Corporation is a Florida firm that handled tax withholding for the clients of MyPayrollHR. After it had processed tax liabilities up to $\$ 9$ million on behalf of the employees of clients of MyPayrollHR, National Payment Corporation learned the bank accounts of MyPayrollHR and its affiliate companies had been frozen. Thereafter, National Payment Corporation sought to recover its losses via the courts and through its insurance company.

On September 10, 2019, the CEO of MyPayrollHR, Michael Mann was arrested and charged with bank fraud. Mr. Mann admitted to a check kiting scheme and fraud in which he owed not just the \$35 million due to Cachet and National Payments Corporation as uncovered in the MyPayrollHR fraud but an additional \$35 million fraudulently borrowed from Bank of America and Pioneer Savings bank via multiple shell firms he created to perpetuate fraud.

\section{RISKS OF OUTSOURCING PAYROLL}

The collapse of MyPayrollHR and the damage it inflicted exposed the lack of adequate regulation over the payroll processing industry. There is currently no regulation that specifically covers payroll companies. Liability for making payroll remains with the employer regardless of whether or not they use a payroll services provider. MyPayrollHR was a NY firm and until a major fraud like the MyPayrollHR occurred; NY state regulators failed to see the need for regulating payroll processors. Payroll processors were seen merely as vendors of the client firms whose payroll they process. Following the MyPayrollHR fraud, some legislators in New York proposed new laws "to regulate payroll processors and impose criminal penalties for misappropriating funds." (Cohn, 2019). In the state of NY, firms have to be licensed with the NY Department of Financial Services (NY DFS) if they "engage in the business of selling or issuing checks, or engage in the business of receiving money for transmission." Not all payroll processors are subject to oversight by the NY DFS. ADP Payroll Services Inc. is licensed as a money transmitter with DFS, while Paychex Inc., based in Rochester, is not. MyPayrollHR was not a licensed money transmitter and hence not subject to oversight by the NY Department of Financial Services. Since the fraud event, the Governor of NY has ordered an investigation into the state's payroll processing industry and the NY DFS has issued subpoenas for over forty payroll processors in the state (Randle, 2019). Oversight of all payroll processors by state departments of financial services are recommended to protect ordinary citizens and the IRS from 
payroll fraud. MyPayrollHR also represents a case of tax fraud since tax payments due to the IRS were also misappropriated and diverted from National Payment Corporation to Mr. Mann's private account.

The fraud at MyPayrollHR highlights the necessity for greater due diligence by firms when they choose to outsource payroll accounting. Firms that had hired MyPayrollHR to do to their payroll processing may not have known that MyPayrollHR had chosen as its third party ACH payments processor Cachet Financial Holdings (CFH). CFH is a firm that had been previously enmeshed in a similar fraud in the state of California. In October 2016, Pinnacle Workforce Solutions a payroll processing firm in Monterey, California, collapsed unexpectedly, after being in business for 25 years. Just as MyPayrollHR did, Pinnacle Workforce Solutions would send Cachet a coded file every pay period instructing Cachet on how to distribute funds. On September 21, 2016, Pinnacle manipulated the code so that the money collected from clients went to Pinnacle instead of being sent to the Cachet holding account. Despite having a shortfall of $\$ 1.3$ million Cachet processed the payroll. On Sept 27, 2016, Pinnacle attempted to repeat the fraud, but this time Cachet refused to process the payroll request and this resulted in a payroll default by client firms (Rahaim, 2017). The Pinnacle fraud almost appears to have provided Michael Mann of MyPayrollHR with a playbook for perpetrating an almost identical fraud which occurred three years after the Pinnacle fraud. It appears Michael Mann had conducted his due diligence of Cachet Financial Systems better than his clients did their due diligence of him and his chosen third party $\mathrm{ACH}$ processor. These frauds are a cautionary tale for SMEs, to examine the history of not just their payroll processors but also the third party $\mathrm{ACH}$ processors that they may partner with. Prior to the MyPayrollHR fraud, Cachet used to process about $\$ 150$ billion in payroll payments for over 110,000 employers. However, six weeks after the MyPayrollHR fraud, on Oct 23, 2019, Cachet notified all its clients that due to "ongoing fraud protocol" with their bank they would be requiring "pre-funding via Direct Wire for all batch entries uploaded this week unless employees were already paid, or tax payments were already transmitted. This included all batch files moving forward." Cachet also said this would be the process until further notice. In a follow up message, the next day, the firm said that transactions uploaded after October 23, 2019, were not being processed and that they were no longer accepting wires. The firm directed its clients to other providers to process payroll.

\section{PREVENTING FUTURE FRAUD EVENTS}

The MyPayrollHR and Pinnacle frauds exposed the vulnerability of the ACH network over which millions of payments are made daily in the USA. According to NACHA in 2019 the ACH network processed 24.7 billion payments which represented a growth of 7.7 percent over the previous year. The value of payments processed in 2019 is estimated at $\$ 55.8$ trillion which represented a growth of nine percent over the previous year. ACH transactions offer a big advantage over wire transfers in that $\mathrm{ACH}$ fees are very small relative to wire transfer fees. However, ACH transactions require a level of trust between the participating financial institutions as there could be a delay of 24-48 hours between when the funds are released to the receiving bank and the funds are made available. The US ACH Network is governed by rules and regulations determined by NACHA which is the National Association of Automated Clearing Houses. NACHA is a self-regulating body and NACHA rules are available for purchase at the NACHA online store at https://www.nacha.org/store?f\%5B0\%5D=topic\%3A99. NACHA rules currently are not freely available as a download. NACHA rules impact the lives of ordinary Americans that directly or indirectly use the NACHA network. It would help with client education and future fraud prevention if NACHA rules would be made freely available to the public.

$\mathrm{ACH}$ processors like Cachet need to stay up to date with NACHA rules. When Cachet attempted to reverse the payroll transfer, not just once but twice, it was violating NACHA rules which prohibit a reversal due to a funding failure. ACH processors like Cachet need to have an internal control mechanism which checks for funding from clients before authorizing payments on their behalf. When fraud events like the MyPayrollHR occur, it makes ACH processor victims like Cachet Financial services, unwilling to assume the risk of processing payroll. On October 23, 2019, when Cachet abruptly announced it would no longer be processing $\mathrm{ACH}$ transactions for numerous payroll providers, it sent hundreds of payroll processors 
scrambling for last minute alternatives including the issuance of paper payroll checks. Preventing fraud events helps to avoid such last-minute disruptions to others.

Clients who hire payroll processors need to enquire if these payroll processors process all payrolls in house or if they use third party ACH operators like Cachet. If they use third party ACH operators like Cachet, then they should additionally query to know about the past history of the third-party firm and to try and learn about any prior history of fraud events or defaults the $\mathrm{ACH}$ operator may have experienced related to processing payroll. This will help the client firm to determine if the third-party firm has adequate internal controls in place to prevent payroll fraud.

Clients of payroll processors need to enquire what internal controls the payment processors have in place to ensure the funds that they deposit with them are sequestered and used only to make authorized payroll payments and not redirected to a private account as Michael Mann did. Subsequent to the MyPayrollHR, other payroll processors like TRICOM have rushed to assure clients that they have adequate internal controls in place to prevent similar frauds from occurring. For example, payroll processors such as TRICOM assure current and future clients that they process everything in-house and that they do not partner with third party processors. They also assure clients that all changes to payroll files have to be approved before being made and changes are independently verified with the client to ensure client accounts have not been hacked. Quality payroll processors have independent external auditors review them and confirm that they are following all regulations and have the necessary internal controls. These are some factors, that client firms should consider and verify, to ensure safety of client funds, when outsourcing payroll processing.

\section{REFERENCES}

Bauer, P., \& Ferrier, G. (1996). Scale Economies, Cost Efficiencies, and Technological Change in Federal Reserve Payments Processing. Journal of Money, Credit and Banking, 28(4), 1004-1039. doi: $10.2307 / 2077938$

Childs, A., Peacock, K., Roe, A., Rush, C., Clenney, A., \& Gramlich, J. (2015). Effortless payroll service offerings. Journal of Accountancy, 220(3), 91-101.

Cohn, M. (2019, October 7). States eye safeguards for payroll processing after MyPayrollHR fraud. AccountingToday.com. Retrieved from https://www.accountingtoday.com/news/states-eyesafeguards-for-payroll-processing-after-mypayrollhr-fraud

Diana, C. (2019, October 1). Beyond MyPayrollHR: Clients of Michel Mann's other payroll companies are out thousands of dollars in tax money. Albany Business Review. Retrieved from https:/www.bizjournals.com/albany/news/2019/10/01/mypayrollhr-michael-mann-payrollcompanies-taxes.html

Krebs, B. (2019, September 11). NY Payroll Company vanishes with \$35 Million. KrebsonSecurity. Retrieved from https://krebsonsecurity.com/2019/09/ny-payroll-company-vanishes-with-35million/

Laverdure, B., \& Mills, T. (2019) Behind the launch of The Clearing House's RTP network: An interview with Timothy Mills. Journal of Payments Strategy and Systems, 13(1), 6-12.

Lubetkin, J. (2008). Online Payroll Services have Changed how CPAs work. CPA Journal, 78(7), 10.

NACHA. (2016, April 18). New NACHA Survey shows Adoption and Awareness of Direct Deposit via ACH Continues to Build. Retrieved from https://www.nacha.org/news/new-nacha-survey-showsadoption-and-awareness-direct-deposit-ach-continues-build

PYMTS. (2019, September 12). MyPayrollHR leaves Users in Limbo with Sudden Closure. Retrieved from https:/www.pymnts.com/news/b2b-payments/2019/mypayrollhr-cachet-shutdown-payroll/

Rahaim, N. (2017, January 19). A federal lawsuit outlines how Pinnacle Workforce Solutions lost millions. Monterey County Weekly.com. Retrieved from https://www.montereycountyweekly.com/news/local_news/a-federal-lawsuit-outlines-howpinnacle-workforce-solutions-lost-millions/article_02 
Randle. A. (2019). \$26 Million in Paychecks, One Mysterious Swindler Charges. Retrieved from https://www.nytimes.com/2019/11/21/nyregion/mypayrollhr-michael-mann.html

Tricom. (2019, September). What the recent MyPayrollHR scandal means for you. Retrieved from https://www.tricom.com/articles/2019/09/what-recent-mypayrollhr-scandal-means-you

Vielkind, J. (2019, October). New York Subpoenas Payroll Firms After MyPayrollHR Collapses. Retrieved from https://www.wsj.com/articles/new-york-subpoenas-payroll-firms-aftermypayrollhr-collapses-11570053236 